\title{
ROUNDTABLE SESSION 1A
}

\section{MONITORING IN CONSERVATION AND MANAGEMENT OF INDIGENOUS CRAYFISH POPULATIONS.}

\author{
D. HOLDICH (England), J. REYNOLDS (Ireland), L. EDSMAN (Sweden)
}

\section{INTRODUCTION}

An important part of any conservation and management strategy for populations of indigenous crayfish species (ICS) is a knowledge of where the crayfish are located; the size of the populations; any threats to their survival, particularly from non-indigenous crayfish species (NICS) and crayfish plague; and what changes are talking place over time. However, how do managers go about monitoring such things?

\section{QUESTIONS TO BE ASKED}

The chairpersons posed the following questions for discussion. Due to time constraints not all were dealt with. However, some answers to those questions not dealt with were provided during subsequent discussions.

1. How best to sample crayfish - how do we know they are there?

2. Should surveying techniques be standardised or not?

3. Can we rely on answers to questionnaires?

4. Best practice?

5. What is a viable population?

6. Heterogeneity and absolute size? How do we measure this?

7. The problem of marginal populations, i.e. at the edge of their range or isolated ones.

8. You cannot conserve or manage crayfish populations without regular monitoring true or false? etc.?

9. Who should do the monitoring - government agencies, researchers, consultants,

10. How often do you need to monitor?

11. Should monitoring also include potential sites where crayfish have not previously been recorded, particularly in order to highlight the threat of new NIC populations?

12. Monitoring and conservation management - do they go hand in hand? 
A number of additional questions were submitted to the Chairpersons. Those not covered by the questions above are given below.

13. What is meant by maintaining " favourable conservation status ", as required by the Habitats Directive for Annex II species in Special Areas of Conservation (SACs)? (F. MARNELL, Ireland).

14. What is the definition of "native »? How long does a species have to be present before it becomes " native "? Or, is it purely dependent on its means of arrival, i.e. natural versus introduction by man? (F. MARNELL, Ireland).

15. How can national distributional data be fed into an European scheme? (M. PÖCKL, Austria).

16. Due to the rapid spread of NICS how can a monitoring scheme ever be up to date? (M. PÖCKL, Austria).

17. Has the use of refuge traps been tested with regard to their success for distribution surveys, or for ascertaining their presence/absence at sites due for development? (P. SIBLEY and J. BYWATER, England).

18. Should we try and produce an atlas of the distribution of indigenous and nonindigenous crayfish in Europe? (D. HOLDICH, England, and P. NÖEL, France).

\section{SOME ANSWERS}

1. It was agreed that a varied sampling method is best in order to ascertain whether crayfish are present or not. This should initially involve stone turning and the use of a net amongst tree roots and marginal vegetation. Particularly in summer months when the water levels are lower crayfish may often be found under stones at the water's edge. If such methods reveal nothing the decision has to be made whether to carry on or not?

The next step would be to use baited traps at least over one night. Traps with inwardly pointing guards at the end of the funnel often prevent crayfish escaping. Additional methods could include night searching with a torch, electrofishing, and the building of artificial refuges. Delegates had mixed views about the usefulness of artificial refuges (see 17. below) and electrofishing. It was also suggested that lures, such as black pudding (made of mammalian blood) and mixed with Vaseline (J. PECKHAM, pers. comm.), could be smeared on rocks and checked at regular intervals - such a method would be more environmentally friendly as the habitat would not be disturbed.

Delegates discussed methods for trying to capture juvenile crayfish. Traps, even when covered in a fine mesh, were not considered very successful, at least for native crayfish. Surber samplers and handnets were considered useful. D. HOLDICH suggested the use of artificial refuges in the form of sacking placed amongst marginal vegetation.

Further details about sampling methods can be found in PEAY (2000), and about crayfish habitat preferences in HOLDICH and ROGERS (2000).

2. It was agreed that this depends on the type of waterbody and what one is trying to find out, e.g. presence/absence, numbers or population structure? L. EDSMAN was in favour of the use of CPUEs, but warned that for comparative purposes this should be done at one site over a period of time as every site tended to be different. 
3. L. EDSMAN said that the value of questionnaires depended on who you were trying to get information from. If it was fishermen then all you need ask was - do you have crayfish? If it was fisheries personnel then a more graded response could be asked for, including which species? It was important to know the date of the record - it was not of much use if it was 10 years old, i.e. the " when I was a child » syndrome! LENNART also pointed out that that a negative response may not always be correct as the person asked may want to keep the information secret if a commercially valuable stock was involved.

4. It was agreed that this was too big a topic to discuss but that the use of some of the methods outlined in 1-3 were essential in any monitoring programme.

5. Delegates agreed that for a population to be considered viable and worthy of conserving status it should be proved to consist of more than one individual. Ideally, all stages of the life-history, including juveniles and berried females, should be shown to be present. However, this would depend on the time of the year the survey was carried out. More than one visit may be required.

A. FERNANDO (Spain) asked how a population could be shown to be declining or increasing. It was agreed that the only way to do this effectively was by means of CPUE.

6. This question was not discussed but D. HOLDICH said that the only true way of finding out the size of a population was to drain the system down if this was at all possible. Multiple trapping and removal or mark-recapture methods could only give estimates, and these were often highly inaccurate.

7. It was suggested that marginal populations could only be discovered by systematic surveys using over grid pattern, and perhaps by talking to local people.

Rather than try and deal with questions 8-12 in the time available, delegates where asked to think about these in connection with any monitoring strategy and communicate with the chairpersons later. Any comments would then be incorporated into the conclusions. Instead questions 13-18 were dealt with.

Some answers to those questions submitted by the audience were then considered.

13. Maintaining favourable conservation status presumably means making sure that the habitat stays favourable for the crayfish to breed in. If a SAC is solely based on crayfish then this should not be too difficult. The Habitat Directive requires all Natura 2000 areas to be protected from deterioration and damage. However, although it supports the principle of sustainable development there is no intention to exclude human activities from SACs. The aim is to ensure that such activities that are undertaken do not threaten the nature conservation interest (ENGLISH NATURE, 2000).

14. This is an interesting question to which there appeared to be no unified answer. D. HOLDICH said that the only reference to this he had seen was by STUBBS (1988), who stated that the terms alien and exotic were usually used for any introduced organism that had not naturally occurred in historical times. He defined « historical times ", for Britain at least, as approximately from the beginning of the Neolithic (ca. 5500 years ago). Therefore, according to D. HOLDICH, presumably anything occurring before 5500 years ago should be considered as native?

15. This is not a problem. If a European mapping scheme gets underway (see 18 . below) then P. NÖEL said that records can be submitted to the Natural History Museum in Paris in a variety of formats and then converted to a UTM grid. The grid could be provided at various levels and rivers can be shown. If the data is sensitive then the level of interrogation, e.g. only at the $50 \times 50 \mathrm{~km}$ squares, can be specified by those supplying the data. 
16. This is true and is a real problem. However, one has to start somewhere. It was agreed that as long as the date of a record was known then it was still useful.

17. Very few delegates had tried this method but those that had said it was not very effective. D. HOLDICH said that he had constructed small weirs made of rocks across streams and that this had proved to be effective, as had the use of sacking to catch juveniles (see 1. above).

18. P. NÖEL said that if delegates agreed he hoped to set up such a scheme through the Natural History Museum in Paris as they had a lot of experienced in such matters and had already produced a number of atlases. D. HOLDICH said that the production of such an atlas depended on records being available for each country. It was clear from the current meeting that many countries had such records. He agreed to e-mail delegates who might be able to help. Delegates were in favour of such a scheme, although they were not sure what period this would cover. It was agreed that records for a certain year would be the best, e.g. 2000, although as long as it was made clear then blocks of years could be used, e.g. 1995-1999. However, the point made by M. PÖCKL under Question 16. above should be noted. L. EDSMAN said that it might be important to protect commercially valuable stocks from trappers. Therefore, the accessibility of the data held in the atlas database should be confined to certain persons.

\section{CONCLUSIONS}

A fruitful discussion was held relating to questions 1-7 and 13-18. Some useful answers were obtained, and comment is made on questions 8-12 below even though time did not allow for their discussion.

It is clear that monitoring has a key role to play in the conservation and management of native crayfish populations, as well as keeping track of the threats to their survival not only from the spread NICS and crayfish plague, but also from actions that might harm their habitat. It was agreed that the more methods that are tried then the more chances there are of finding crayfish in surveys.

Monitoring does not only involve locating populations, but assessing their continued presence, and population size, over time if possible. Threats from NICS cannot be properly assessed unless potential sites where they have not been recorded before are monitored.

It is clear that you cannot conserve or manage crayfish populations without regular monitoring. How often this is done depends on resources - both financial and the availability of surveyors. Ideally, a population of native crayfish inhabiting a SAC should be monitored at least once a year. The time of year this is carried out may again be determined by resources, e.g. funds are released but have to be spent in a short space of time. Ideally during surveys crayfish should be disturbed as little as possible if they are at a susceptible stage, e.g. mating and moulting periods, and the overwintering egg incubation period. Even if young of the year are not found during a survey then the previous year's young should be available and thus indicate that the population is breeding.

In order for the most comprehensive picture of crayfish distribution to be obtained then government agencies, researchers, consultants etc. should all be involved. However, with such a scenario then a certain amount of « politics » may be encountered by those trying to collate records. It is likely that any attempt to produce an atlas of crayfish distribution in Europe will be fraught with difficulties but, with everybody's cooperation, it should be possible. As a first step HOLDICH (2002) provides an overview of the distribution of ICS and NICS in Europe based on an extensive literature search.

Do monitoring and conservation management go hand in hand? Definitely! 


\section{ACKNOWLEDGEMENTS}

Thanks to all those who participated in and helped with the translation for Roundtable Session $1 \mathrm{~A}$.

\section{REFERENCES}

ENGLISH NATURE, 2000. The Habitats Directive. English Nature, Peterborough, $12 \mathrm{p}$.

HOLDICH D.M., 2002. Distribution of crayfish in Europe and some adjoining countries. Bull. Fr. Pêche Piscic., 367, 611-650.

HOLDICH D.M., ROGERS W.D., 2000. Habitat requirements of the white-clawed crayfish, Austropotamobius pallipes. In : ROGERS D., BRICKLAND J., Crayfish Conference Leeds, Environment Agency, English Nature and the International Association of Astacology, 109-121.

PEAY S., 2000. Guidance on works affecting white-clawed crayfish. English Nature and the Environment Agency, $27 \mathrm{p}$.

STUBBS D., 1988. Towards an introductions policy. Conservation guidelines for the introduction and reintroduction of living organisms into the wild in Great Britain. London, Wildlife Link, $48 \mathrm{p}$. 